\title{
EFEKTIVITAS PROGRAM BINA KELUARGA LANSIA (BKL) DALAM MEMBINA LANSIA DI KECAMATAN GODEAN SLEMAN YOGYAKARTA
}

\author{
Enik Listyaningsih ${ }^{1}$, Agaphita Chrisinta Wardani ${ }^{2}$ \\ ${ }^{(1,2)}$ STIKES Bethesda Yakkum Jl. Johar Nurhadi No. 6 Yogyakarta 524565 \\ Email: enik@stikesbethesda.ac.id
}

\begin{abstract}
ABSTRAK
Latar Belakang: Menurut Wiranatakusuma (BKKBN, 2012:9) Indonesia mengalami peningkatan jumlah penduduk berusia 60 tahun ke atas cukup pesat. Dengan demikian diperlukan kesiapan dan peran keluarga yang mempunyai lansia untuk membinanya melalui kelompok kegiatan BKL. Tujuan Penelitian: Untuk mengetahui efektivitas program BKL dalam membina lansia di Kecamatan Godean, Sleman, Yogyakarta tahun 2017. Metode Penelitian: Metode kualitatif dengan jenis penelitian deskriptif. Sampel 6 BKL, setiap BKL diambil 2 kader, 2 keluarga lansia, 2 lansia, peneliti menggunakan teknik purposive sampling. Pengambilan data menggunakan wawancara mendalam. Alat ukur peneliti sendiri, pedoman wawancara, alat perekam dan alat tulis. Hasil: Bina Keluarga Lansia (BKL) ini efektif dilihat dari hasil wawancara $6 \mathrm{BKL}$ yang setiap BKL diambil 2 kader, 2 keluarga lansia dan 2 lansia tentang keberhasilan program, kepuasan terhadap program dan pencapaian tujuan berdasarkan adanya indikator rutinitas kegiatan program BKL, tingkat partisipasi keluarga lansia dan lansia dalam mengikuti program BKL. Hasil wawancara semua responden menjawab kegiatannya rutin, peserta yang datang lebih dari $75 \%$ dan kegiatan yang dilakukan di BKL sangat membantu dalam membina lansia. Kesimpulan: Setelah disimpulkan mengenai efektivitas program BKL dalam membina lansia yang dilihat dari keberhasilan program, kepuasan program dan pencapaian program bahwa BKL ini efektif untuk membina lansia. Saran: Diharapkan peneliti selanjutnya dapat meneliti BKL dengan menggabungkan metode kualitatif dan kuantitatif.
\end{abstract}

Kata kunci: Efektivitas - Bina Keluarga Lansia

\section{ABSTRACT}

Background: Based on Wiranatakusuma (on BKKBN, 2012:9), the population of elderly with the age of 60 or more was increasing rapidly. Therefore, readiness and family role are needed to nurture the elderly by having Bina Keluarga Lansia (BKL). Research Objectives: To know the effectiveness of BKL program to nurture the elderly in Godean Sleman Yogyakarta in 2017. Research Method: It was a qualitative method with descriptive research type. There was 6 sampel taken from each BKL, 2 cadres, 2 elderly family and 2 elderly. The researcher used purposive sampling technique. Data gathering used deep interview. The measuring instrument was the researcher it self with an interview guideline, voice recorder and stationery. Result: $B K L$ was effective. It could be seen from the interview result from $6 B K L$, in which in each BKL, 2 cadres, 2 eldery and 2 eldery family eldery were taken about the success, satisfaction and achievement of the program based on the indicator of BKL program routinity, the participation from elderly family and elderly in joining the program and activity types done by BKL program. The interview result shows that the program is routine, the participation is good and the activity in BKL is very useful in nuturing the elderly. Conclusions: After concluding the effectiveness of $B K L$ program in nuturing the elderly which could be seen from the success, satisfaction and achievement of the program, BKL is effective in nuturing the elderly. Suggestion: Further researchers are expected to research $B K L$ by combining quantitative and qualitative methods.

Keywords: Effectivenees - Bina Keluarga Lansia 


\section{PENDAHULUAN}

Sensus penduduk tahun 2010 menunjukkan bahwa Indonesia termasuk lima besar negara di dunia dengan jumlah penduduk lanjut usia terbanyak yakni 181,9 juta jiwa atau 9,6 persen dari total penduduk Indonesia. Menurut Wiranatakusuma (dalam Badan Kependudukan Keluarga Berencana Nasional, 2012:9) Indonesia mengalami peningkatan jumlah dan populasi penduduk berusia 60 tahun ke atas cukup pesat. Dengan meningkatnya jumlah lansia maka perhatian terhadap lansia perlu ditingkatkan agar terwujud kualitas kehidupan lansia yang sejahtera. Dengan demikian diperlukan kesiapan dan peran keluarga yang mempunyai lansia untuk membinanya melalui kelompok kegiatan Bina Keluarga Lansia (BKL).

Bina Keluarga Lansia (BKL) adalah kelompok kegiatan yang dilakukan untuk meningkatkan ketrampilan keluarga yang mempunyai keluarga dalam pengasuhan, perawatan, pemberdayaan lansia agar dapat meningkatkan kesejahteraannya dengan cara pembinaan fisik, pembinaan psikis atau mental, pembinaan keagamaan, memberikan fasilitas atau kemudahan bagi lansia untuk mengamalkan kemampuan dan ketrampilan yang dimiliki (BKKBN, 2012: 10). Di Indonesia Bina Keluarga Lansia (BKL) terbentuk sejak tahun 1998. Adanya BKL di masyarakat dapat menjadi wadah kelompok kegiatan untuk memperdayakan lansia melalui berbagai kegiatan dengan dukungan dari masyarakat dan keluarga yang memiliki lansia untuk menjadikan keluarga sebagai pembina lansia dalam rumah tangganya.
Daerah Istimewa Yogyakarta memiliki berbagai kelompok BKL yang berada di wilayah kota Yogyakarta, Kabupaten Sleman, Kabupaten Bantul, Kabupaten Gunungkidul dan Kabupaten Kulonprogo. Pada tahun 2012 jumlah penduduk lansia tertinggi berada di D.I. Yogyakarta (13,04\%). Usia harapan hidup di DIY pada tahun 2011 adalah 73,27 tahun (Dinkes DIY, 2013). Di Kabupaten Sleman jumlah lansia pada tahun 2011 mencapai 152.478 jiwa $(13,54 \%)$ dari jumlah penduduk sebesar 1.125.369 dengan usia harapan hidup lebih dari 75 tahun (Badan Pusat Statistik Sleman, 2012).

Kecamatan Godean yang berada di Jl. Godean km 9,5, Sidoagung, Godean, Sleman, Yogyakarta, yang terdiri dari 7 kelurahan dan 17 dusun ini terdapat beberapa kelompok BKL yang masih aktif sampai sekarang dengan jumlah lansia 792 jiwa yang berusia 60 tahun sampai 90 tahun. Berdasarkan studi pendahuluan pada tanggal 21 November 2016 penulis mendapatkan keterangan dari sekertaris Kecamatan Godean, terhitung pada tahun 2016 ini ada 12 kelompok BKL tersebar di Kecamatan Godean yang telah terbentuk sejak tahun 2012. Jumlah kader BKL ada 24 dan jumlah keluarga lansia ada 384 yang mengikuti program BKL.

BKL yang masih rutin melakukan kegiatan yaitu BKL di Sidoagung, BKL di Sidoluhur, BKL di Sidoarum, BKL di Sidokarto. BKL tersebut aktif dalam melakukan pemberdayaan lansia, sedangkan yang jarang melakukan kegiatan BKL yaitu BKL di Sidomoyo yang diberi nama Bugenvil dan Wreda Mulya dan BKL di Sidomulyo yang diberi nama Harapan Mulia, dikarenakan sudah tidak ada yang 
mengurus dan tidak dikembangkan lagi.

\section{METODE PENELITIAN}

Metode kualitatif dengan jenis penelitian deskriptif. Sampel 6 BKL, setiap BKL diambil 2 kader, 2 keluarga lansia, 2 lansia, peneliti menggunakan teknik purposive sampling. Pengambilan data menggunakan wawancara mendalam. Alat ukur peneliti sendiri, pedoman wawancara, alat perekam dan alat tulis.

\section{HASIL PENELITIAN DAN PEMBA- HASAN}

\section{Keberhasailan Program BKL}

Berdasarkan hasil wawancara dari 36 responden semua responden menjawab program BKL di Sidoluhur, Sidoagung, Sidokarto dan Sidoarum berhasil dilihat dari rutinitas pelaksanaan kegiatan yang dilakukan satu kali satu bulan, peserta yang datang lebih dari 75\%, kegiatan yang sudah direncanakan semua dapat dilakukan. Peneliti berpendapat bahwa efektivitas dapat dilihat dari keberhasilan program melalui rutinitas kegiatan, jumlah peserta yang hadir dan tujuan yang tercapai.

Menurut Musaroh (2010: 13) efektivitas dikatakan efektif dapat dilihat dari tingkat keberhasilan, berhasil jika suatu organisasi atau suatu program dapat melaksanakan fungsinya atau tugasnya dengan baik. Suatu program dikatakan berhasil jika tujuannya tercapai dan waktu pelaksanaannya sesuai (Starawaji,2009).

Hasil penelitian ini didukung oleh penelitian yang dilakukan oleh Hadriah Olesman, MS (2015), dapat diketahui bahwa Efektivitas Kelompok B K L dilihat dari keaktifan anggota BKL.

2. Kepuasan terhahadap Program BKL

Berdasarkan hasil wawancara dari 36 responden semua responden mengatakan bahwa responden merasa puas dengan adanya program BKL, karena program BKL dapat membantu keluarga yang mempunyai lansia untuk memecahkan permasalahan yang dialami lansia dan lansia menjadi sejahtera. Peneliti berpendapat efektivitas dapat dilihat dari kepuasan responden terhadap program bahwa program tersebut dapat membantu menyelesaikan masalah lansia.

Menurut Bungkaes (2013) kepuasan menunjukkan sampai sejauh mana organisasi dapat memenuhi kebutuhan para konsumen. Menurut Starawaji (2009) pengukuran efektivitas dapat diukur dengan kepuasan responden terhadap suatu organisasi atau program.

Hasil penelitian ini didukung oleh hasil penelitian yang dilakukan Junadi (2017), bahwa BKL sangat bermanfaat khususnya lansia karena sudah mendapat bimbingan dan motivasi yang ditunjukkan dengan merasakan badan menjadi lebih sehat dan kuat, mandiri, produktif serta bermanfaat bagi lingkungan sehingga terwujud keluarga lansia yang tangguh.

3. Pencapaian Tujuan

Berdasarkan hasil wawancara dari 36 responden semua responden menjawab bahwa program BKL di Sidoluhur, Sidoagung, Sidokarto dan Sidoarum 
tujuannya tercapai dilihat dari tingkat partisipasi dan kepedulian keluarga yang mempunyai lansia untuk mengikuti kegiatan BKL, lansia merasa dipedulikan kesehatannya, mandiri dan sejahtera. Peneliti berpendapat bahwa tujuan BKL tercapai karena adanya kepedulian keluarga yang mempunyai lansia untuk membina lansia supaya lansia mandiri, sehat dan sejahtera.

Menurut BKKBN (2012:11) bahwa tujuan BKL adalah meningkatkan kepedulian dan peran keluarga dalam mewujudkan lanjut usia sejahtera yang bertaqwa kepada Tuhan Yang Maha Esa, hidup sehat, mandiri, produktif dan bermanfaat bagi keluarga dan masyarakat. Menurut Muasaroh (2010: 13) suatu program dikatakan efektif dari sudut hasil jika tujuan program tersebut dapat dicapai.

Hasil penelitian ini didukung oleh hasil penelitian yang dilakukan Febriyanti (2016), bahwa partisipasi lansia diwujudkan dengan adanya keikutsertaan lansia dalam mempromosikan usaha sesama lansia sehingga lansia dapat hidup mandiri.

\section{KESIMPULAN}

Sesuai dengan tujuan penelitian, analisis data dan pembahasan pada penelitian dengan judul "Efektivitas Program Bina Keluarga Lansia (BKL) dalam Membina Lansia di Kecamatan Godean Sleman Yogyakarta Tahun 2017”, maka dapat disimpulkan bahwa:

1. Keberhasilan program BKL menunjukkan bahwa program BKL efektif dilihat dari rutinitas pelaksanaan yang dilakukan satu bulan satu kali, kehadiran peserta lebih dari $75 \%$, kegiatan yang direncanakan semua dapat dijalankan.

2. Kepuasan program BKL menunjukkan bahwa program BKL efektif dilihat dengan adanya program BKL dapat membantu keluarga yang mempunyai lansia untuk memecahkan permasalahan yang dihadapi lansia dan lansia juga merasa lebih sejahtera dengan adanya program BKL.

3. Pencapaian Tujuan menunjukkan bahwa program BKL efektif dengan dilihat dari meningkatkan kepedulian dan peran keluarga dalam mewujudkan lanjut usia sejahtera, hidup sehat dan mandiri.

\section{SARAN}

1. Bagi Bina Keluarga Lansia (BKL) di Kecamatan Godean

a. Diharapkan 6 BKL yang sudah aktif, yaitu BKL di Sidoluhur, Sidoagung, Sidokarto dan Sidoarum tetap mempertahankan kegiatan-kegiatan yang sudah berjalan dengan baik.

b. Diharapkan 6 BKL yang belum rutin melakukan kegiatan, yaitu BKL Sidorejo, Sidomulyo dan Sidomoyo supaya mengaktifkan meningkatkan kegiatan BKL.

2. Bagi STIKES Bethesda Yakkum Yogyakarta

Hasil dari penelitian ini dapat menjadi referensi dan sebagai panel pendidikan bagi profesi keperawatan yaitu 
mengenai efektivitas program BKL dalam membina lansia.

3. Bagi peneliti selanjutnya yang meneliti tentang BKL

a. Dapat dijadikan dasar dalam pengembangan penelitian selanjutnya.

b. Diharapkan peneliti selanjutnya dapat meneliti program BKL dengan metode lain, menggabungkan metode kualitatif dan kuantitatif.

\section{DAFTAR PUSTAKA}

BKKBN. 2012. Survei demografi dan kesehatan Indonesia. Jakarta: BKKBN.

Badan Pusat Statistik (BPS). 2012. Kabupaten Sleman Dalam Angka. Badan Statistik: Sleman.

Bungkaes. 2013. Hubungan Efektivitas Pengelolaan Program Raskin

Dengan Peningkatan Kesejahteraan Masyarakat Di Desa Manahan Kecamatan Gemeh Kabupaten Kepulauan Talaud. Manado, Universitas Sam Ratulangi.

Dinas Kesehatan Daerah Istimewa Yogyakarta. 2013. Profil Kesehatan Provinsi Daerah Istimewa Yogyakarta Tahun 2012. Yogyakarta: Dinas Kesehatan Yogyakarta.

Dra. Hadriah, dkk. 2015. Studi Efektivitas Kelompok Kegiatan Tribina: BKB, BKR, BKL Sumatera Utara, Jawa Tengah dan Sulawesi Utara.

Febriyati. 2016. Pemberdayaan Lansia Melalui Usaha Ekonomi Produktif Oleh Bina Keluarga Lansia (BKL) Mugi Waras Dusun Blendung Desa Sumbersari Kecamatan Moyudan
Kabupaten Sleman.

Junadi. 2017. Penyuluhan Kelompok Bina Keluarga Lansia (BKL) dalam Mewujudkan Keluarga Lansia Tangguh Di Kecamatan Malo Kabupaten Bojonegoro.

Muasaroh. 2010. http://literaturbook. pengertian-efektivitas-dan-landasan [15 Desember 2015] 